Check for updates

Cite this: RSC Adv., 2017, 7, 20201

\section{Size- and composition-controlled Pt-Sn bimetallic nanoparticles prepared by atomic layer deposition $\dagger$}

\author{
Ranjith K. Ramachandran, (D) ${ }^{a}$ Matthias Filez, $\dot{t}^{\mathrm{b}}$ Jolien Dendooven, ${ }^{\mathrm{a}}$ \\ Vladimir V. Galvita, ${ }^{\mathrm{b}}$ Hilde Poelman, (D) ${ }^{\mathrm{c}}$ Eduardo Solano, ${ }^{\mathrm{a}}$ Emiliano Fonda, ${ }^{\mathrm{c}}$ \\ Guy B. Marin ${ }^{\mathrm{b}}$ and Christophe Detavernier ${ }^{\star a}$
}

Pt-Sn bimetallic nanoparticles (BMNPs) are used in a variety of catalytic reactions and are widely accepted as a model system for Pt-based bimetallics in fundamental catalysis research. Here, Pt-Sn BMNPs were prepared via a two-step synthesis procedure combining atomic layer deposition (ALD) and temperature programmed reduction (TPR). In situ X-ray diffraction measurements during TPR and ex situ X-ray absorption spectroscopy at the $\mathrm{Pt} \mathrm{L}_{\mathrm{III}}$-edge revealed the formation of $\mathrm{Pt}-\mathrm{Sn}$ bimetallic alloys with a phase determined by the $\mathrm{Pt} /(\mathrm{Pt}+\mathrm{Sn})$ atomic ratio of the as-deposited bilayer. The size of the BMNPs could be tuned by changing the total thickness of the bilayers, while keeping the $\mathrm{Pt} /(\mathrm{Pt}+\mathrm{Sn})$ atomic ratio constant. Due to the exceptional control over BMNP size and crystalline phase, the proposed method will enable highly systematic studies of the relation between the structure and the performance of Pt-Sn bimetallic catalysts.

Received 5th February 2017

DOI: 10.1039/c7ra01463e

rsc.li/rsc-advances

\section{Introduction}

Pt-Sn bimetallic catalysts are highly performant in a variety of catalytic reactions, including (de)hydrogenation and oxidation of hydrocarbons. ${ }^{1}$ In industry, for example, they are used worldwide in the Oleflex (UOP) process for the on-purpose production of propylene. ${ }^{2}$ Besides their wide applicability, Pt-Sn catalysts have become quintessential model systems in catalysis science as a result of several decades of intense research. In this research history, academia as well as industry have tried to understand the role of the promoting element (Sn) on the overall performance of Pt-based bimetallic catalysts in particular, and metal catalysts in general. ${ }^{3,4}$ Despite their merits, full elucidation of structureperformance relationships has only been obtained in rare cases, due to the non-uniform nature of the alloyed nanoparticle phase. ${ }^{5,6}$ More particularly, conventional methods for bimetallic catalyst synthesis - wet impregnation and precipitation - introduce compositional and particle size heterogeneities, hindering

${ }^{a}$ Department of Solid State Sciences, COCOON, Ghent University, Krijgslaan 281/S1, B-9000 Ghent, Belgium. E-mail: Christophe.Detavernier@UGent.be

${ }^{b}$ Laboratory for Chemical Technology, Ghent University, Technologiepark 914, B-9052 Ghent, Belgium

'Synchrotron SOLEIL, SAMBA Beamline, L'Orme des Merisiers, Saint-Aubin, BP48, 91192 Gif-sur-Yvette, France

$\dagger$ Electronic supplementary information (ESI) available: Experimental section; XRD patterns and particle size distributions of differently sized $\mathrm{Pt}_{3} \mathrm{Sn}$ nanoparticles. See DOI: 10.1039/c7ra01463e

$\$$ Present address: Inorganic Chemistry and Catalysis group, Debye Institute for Nanomaterials Science, Utrecht University, Universiteitsweg 99, 3584 CG Utrecht, The Netherlands. unambiguous disentanglement of structure-performance relationships. This missing link between nano-alloy structure, reaction mechanism and the catalyst performance impedes the redesign of current bimetallic catalysts. The fabrication of fundamentally improved bimetallic catalysts therefore relies on the synthesis of bimetallic catalysts which allows for control over the bimetallic nanoparticle (BMNP) composition and particle size. Recently, there have been reports on the controlled synthesis of Pt-Sn nanoparticles employing solution phase methods. While Wang et al. ${ }^{7}$ reported on controlling the shape of colloidal Pt-Sn nanoparticles, DeSario et al. ${ }^{8}$ focussed on the low temperature crystallization and ordering in alloys with different compositions.

Here, we demonstrate the simultaneous control on both size and composition of the Pt-Sn nanoparticles via a vapor phase method called atomic layer deposition (ALD). ${ }^{\mathbf{9}, 10}$ A crucial advantage of ALD is that the amount of deposited material can be controlled at the monolayer level by changing the number of ALD cycles. This is a consequence of the self-limiting nature of the surface reactions determining the ALD process. Moreover, this unique surface chemistry enables conformal depositions on 3D substrates, including mesoporous supports with large surface areas. ${ }^{\mathbf{1 1}}$

Until recently, the ALD-based synthesis of BMNPs was limited to combinations of two noble metals. ${ }^{12-15}$ Several groups exploited two characteristics typical of noble metal ALD processes, in casu the island growth mode ${ }^{\mathbf{1 6 , 1 7}}$ and their selective deposition onto other noble metal over oxide sites, ${ }^{\mathbf{1 4 , 1 8 , 1 9}}$ to grow Pt-Pd, Pt-Ru and Pd-Ru BMNPs. To broaden the range of possible alloying elements for Pt-based BMNPs, we recently 


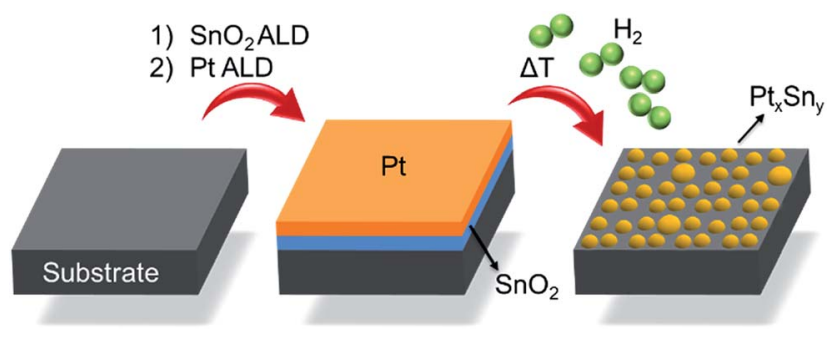

Fig. 1 Schematic representation of the ALD-based Pt-Sn BMNPS synthesis.

reported an ALD-based synthesis strategy that allows for the size- and composition-controlled preparation of BMNPs containing a non-noble metal next to a noble metal, namely Pt-In and Pt-Ga systems. ${ }^{20}$ In this work, the generality of the method is further demonstrated by providing proof for its applicability to Pt-Sn BMNPs. Future fundamental catalysis studies, generally employing the Pt-Sn model system, will highly benefit from the atomically precise control over composition and size offered by the ALD method.

Fig. 1 schematically describes the steps involved in the fabrication process of the Pt-Sn BMNPs. First, thin films of $\mathrm{SnO}_{2}$ and Pt are sequentially deposited on a silica substrate by means of ALD, using alternating exposures of tetrakis-(dimethylamino)tin and $\mathrm{H}_{2} \mathrm{O}$ for $\mathrm{SnO}_{2} \mathrm{ALD}^{21}$ and trimethyl-(methylcyclopentadienyl)platinum and $\mathrm{O}_{3}$ for $\mathrm{Pt} \mathrm{ALD},{ }^{16,22}$ yielding a Pt/ $\mathrm{SnO}_{2}$ bilayer structure. These bilayers are then subjected to a temperature programmed reduction (TPR) to $700{ }^{\circ} \mathrm{C}$ in $10 \%$ $\mathrm{H}_{2} / \mathrm{N}_{2}$ at a heating rate of $0.2{ }^{\circ} \mathrm{C} \mathrm{s}^{-1}$, which results in the formation of alloyed Pt-Sn particles. The composition and size of the BMNPs can be controlled by profiting from the atomic level thickness control of the ALD technique.

\section{Experimental}

\section{Sample preparation}

All depositions were performed at $150{ }^{\circ} \mathrm{C}$ in a home-built coldwall ALD chamber ${ }^{16,23,24}$ with a base pressure of $10^{-6}$ mbar. Si wafers with a $100 \mathrm{~nm}$ thermally grown $\mathrm{SiO}_{2}$ layer on top were used as substrates. $\mathrm{SnO}_{2}$ and Pt were deposited using alternating exposures of TDMASn ( $99 \%$, Strem Chemicals) and $\mathrm{H}_{2} \mathrm{O}$ for $\mathrm{SnO}_{2}$
$\mathrm{ALD}^{21}$ and (MeCp)PtMe ${ }_{3}$ (99\%, Strem Chemicals) and $\mathrm{O}_{3}$ for $\mathrm{Pt}$ ALD. ${ }^{16} \mathrm{Ar}$ with $99.999 \%$ purity was used as a carrier gas for all precursors. $\mathrm{O}_{3}$ was produced from a $99 \% \mathrm{O}_{2} / \mathrm{N}_{2}$ mixture with an AC-2025 (USA Inc.) generator, resulting in an $\mathrm{O}_{3}$ concentration of $200 \mu \mathrm{g} \mathrm{ml}^{-1}$. A typical $\mathrm{SnO}_{2}$ ALD cycle lasted $20 \mathrm{~s}$ with $5 \mathrm{~s}$ pulse time for both the precursor and reactant, and $5 \mathrm{~s}$ pumping after each pulse. For Pt ALD, a static exposure mode was applied during both ALD half-cycles, resulting in a total cycle time of $50 \mathrm{~s}$.

\section{Composition determination}

$\mathrm{Pt}$ and $\mathrm{SnO}_{2}$ film thicknesses were determined by X-ray reflectivity measurements using a Bruker D8 Discover system with $\mathrm{Cu}$ $\mathrm{K} \alpha$ radiation. Alternatively, the thickness was extracted from calibrated X-ray fluorescence data obtained with a Bruker Artax system with Mo X-ray source. From the thickness, the specific weight of the Pt and Sn was calculated by assuming the densities of the films equal to that of bulk Pt and $\mathrm{SnO}_{2}$, respectively (see ESI $\dagger$ for the details).

In situ X-ray diffraction. The TPR treatment of the $\mathrm{Pt} / \mathrm{SnO}_{2}$ bilayers was performed under $10 \% \quad \mathrm{H}_{2} / \mathrm{N}_{2}$ atmosphere in a home-built heating chamber mounted on a Bruker D8 diffractometer ${ }^{25,26}$ to enable in situ XRD characterization. A linear detector covering $20^{\circ}$ in $2 \theta$ was used to collect the diffracted X-rays with a $2 \mathrm{~s}$ time resolution.

X-ray absorption spectroscopy. XAS measurements were performed at the SAMBA beamline of the SOLEIL synchrotron (Saint-Aubin, France) operating at $450 \mathrm{~mA}$. All experiments were performed in fluorescence mode at the Pt $\mathrm{L}_{\mathrm{III}}$ edge $(E=11564$ $\mathrm{eV}$ ) using a 35-element Ge detector (Canberra). XAS data reduction and analysis were executed with the Demeter 0.9.13 software package by following the methodology of Koningsberger $e t$ al. ${ }^{27}$

Electron microscopy. SEM measurements were performed on a FEI Quanta $200 \mathrm{~F}$ and a FEI Sirion instrument. The analysis of the SEM images was done using the ImageJ software, providing particle size distributions. The reported average particle sizes and standard deviations were calculated from a Gaussian fit to the particle size distributions (see ESI $\dagger$ for the details).

\section{Results and discussion}

A series of bilayer samples with different $\mathrm{Pt} /(\mathrm{Pt}+\mathrm{Sn})$ atomic ratios was prepared by using the atomic level control of ALD to

Table 1 Characterization of Pt-Sn samples prepared for demonstrating the composition control. The atomic ratio was determined by XRF (see ESI), the crystalline phase by XRD and the fractional Pt coordination numbers by EXAFS analysis (the error on the EXAFS coordination numbers is $\sim 10 \%$ ). Dominant phases are marked $(*)$

\begin{tabular}{|c|c|c|c|c|c|c|}
\hline \multirow[b]{2}{*}{ Sample ID } & \multicolumn{2}{|c|}{ Thickness (nm) } & \multirow{2}{*}{$\begin{array}{l}\mathrm{Pt} /(\mathrm{Pt}+\mathrm{Sn}) \\
\text { atomic ratio }\end{array}$} & \multirow{2}{*}{$\begin{array}{l}\text { Phase }(\mathrm{s}) \text { formed } \\
\text { after TPR }\end{array}$} & \multicolumn{2}{|c|}{$\begin{array}{l}\text { Fractional Pt } \\
\text { coordination numbers }\end{array}$} \\
\hline & $\mathrm{SnO}_{2}$ & $\mathrm{Pt}$ & & & $n_{\mathrm{Pt}-\mathrm{Pt}}$ & $n_{\mathrm{Pt}-\mathrm{Sn}}$ \\
\hline a & 2.1 & 5.5 & 87 & $\mathrm{Pt}^{*}, \mathrm{Pt}_{3} \mathrm{Sn}$ & 0.81 & 0.19 \\
\hline $\mathrm{b}$ & 4.4 & 5.5 & 75 & $\mathrm{Pt}_{3} \mathrm{Sn}$ & 0.62 & 0.38 \\
\hline c & 7.9 & 5.5 & 63 & $\mathrm{Pt}_{3} \mathrm{Sn}^{*}, \mathrm{PtSn}$ & 0.58 & 0.42 \\
\hline d & 7.9 & 3.8 & 54 & $\mathrm{Pt}_{3} \mathrm{Sn}, \mathrm{PtSn} *$ & 0.45 & 0.55 \\
\hline e & 4.4 & 1.7 & 47 & PtSn & 0.20 & 0.80 \\
\hline $\mathrm{f}$ & 7.9 & 1.0 & 22 & $\mathrm{PtSn}_{4}, \mathrm{Sn}$ & - & - \\
\hline
\end{tabular}


precisely define the thickness of $\mathrm{SnO}_{2}$ and Pt layers (Table 1, samples a-f). In situ XRD patterns collected during $\mathrm{H}_{2}$ TPR of the as-deposited bilayers a-d show similar phase evolution behavior (Fig. 2A). Initially, the patterns show a diffraction peak which corresponds to metallic $\mathrm{Pt}(111)$. No diffractions corresponding to $\mathrm{SnO}_{2}$ are observed, as a consequence of its amorphous structure. As the temperature increases, a gradual shift of the $\mathrm{Pt}(111)$ peak towards a lower $2 \theta$ angle occurs around $250{ }^{\circ} \mathrm{C}$, resulting from the incorporation of reduced $\mathrm{Sn}$ into the $\mathrm{Pt}$ fcc lattice. ${ }^{28}$ The diffraction peaks at higher temperatures show that the uptake of reduced $\mathrm{Sn}$ results in the formation of PtSn intermetallic alloys. For sample e with a $\mathrm{Pt} /(\mathrm{Pt}+\mathrm{Sn})$ atomic ratio of $47 \%$, the formation of the crystalline alloy phase happens

A (a) $\mathrm{Pt} /(\mathrm{Pt}+\mathrm{Sn})=87 \%$

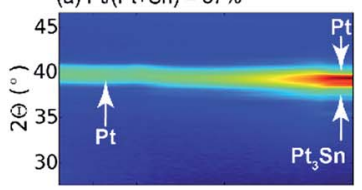

(b) $\mathrm{Pt}(\mathrm{Pt}+\mathrm{Sn})=75 \%$

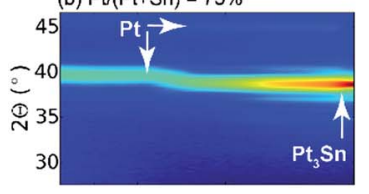

(c) $\mathrm{Pt} /(\mathrm{Pt}+\mathrm{Sn})=63 \%$

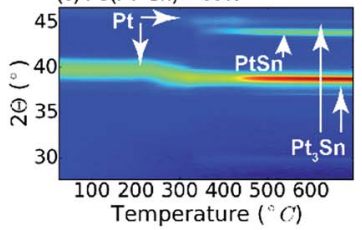

B

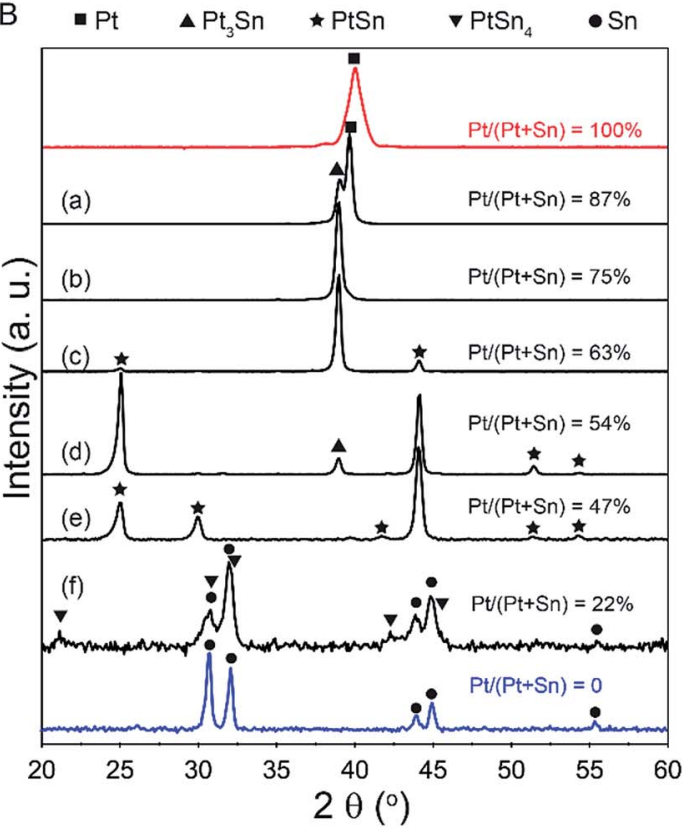

Fig. 2 (A) In situ XRD patterns during TPR in $10 \% \mathrm{H}_{2} / \mathrm{N}_{2}$ of $\mathrm{Pt} / \mathrm{SnO}_{2}$ bilayer samples with $\mathrm{Pt} /(\mathrm{Pt}+\mathrm{Sn}$ ) atomic ratios of (a) $87 \%$, (b) $75 \%$, (c) $63 \%$, (d) $54 \%$, (e) $47 \%$ and (f) $22 \%$. (B) Ex situ XRD patterns measured after the TPR experiment. The red and blue patterns are measured after TPR of pure Pt and $\mathrm{SnO}_{2}$ layers, respectively. more abrupt at a temperature of $200{ }^{\circ} \mathrm{C}$. In the case of the most $\mathrm{Sn}$ rich sample, sample $\mathrm{f}$, there are no diffraction peaks visible initially, as the amount of Pt is under the detection limit of XRD. When the temperature reaches $500{ }^{\circ} \mathrm{C}$, two diffractions corresponding to the $\mathrm{PtSn}_{4}$ phase appear and disappear as this phase is not stable above $522{ }^{\circ} \mathrm{C}$. The absence of diffractions from $\mathrm{SnO}_{2}$ in the in situ XRD patterns indicates that the as-deposited amorphous $\mathrm{SnO}_{2}$ is reduced to $\mathrm{Sn}$ before being crystallized. Sn is also not visible as it is liquid at higher temperatures. ${ }^{29}$

The ex situ XRD measurements after TPR and cool down (Fig. 2B) allow to pinpoint the exact Pt-Sn alloy phases for differently composed bilayers at room temperature (Table 1). There is a clear relation between the $\mathrm{Pt} /(\mathrm{Pt}+\mathrm{Sn})$ atomic ratio of the as-deposited bilayers and their eventual Pt-Sn alloy composition/phase. A gradual transformation from Pt towards metallic Sn is observed, demonstrating the exceptional ability of ALD to tune the phase of bimetallic Pt-Sn alloys. For sample $\mathrm{f}$, diffractions corresponding to metallic $\mathrm{Sn}$ are observed in addition to the $\mathrm{PtSn}_{4}$ peaks.

Ex situ $\mathrm{Pt} \mathrm{L}_{\mathrm{III}}$ edge extended X-ray absorption fine structure (EXAFS) data of the reduced samples (Fig. 3) furnish a detailed insight into the local atomic structure of the alloys, except for sample $f$ for which the quality of the measured EXAFS data was too low for analysis. Qualitative analysis of the features in the higher $R$-range $(R>3 \AA)$ reveals an fcc structure for samples a and b which gradually disappears for samples with lower Pt content. Because $\mathrm{Pt}$ and $\mathrm{Pt}_{3} \mathrm{Sn}$ have fcc lattice stacking, this result is in agreement with the long-range XRD data. Quantitative modeling of the EXAFS data with a Pt-Pt and Pt-Sn shell yields good agreement with the experimental signal for $R$ in the 2-3 A range. Pt-Sn alloying was assessed by deriving the fractional Pt coordination numbers $\left(n_{\mathrm{Pt}-\mathrm{Pt}}=N_{\mathrm{Pt}-\mathrm{Pt}} /\left(N_{\mathrm{Pt}-\mathrm{Sn}}+\mathrm{N}_{\mathrm{Pt}-\mathrm{Pt}}\right)\right.$ and $n_{\mathrm{Pt}-\mathrm{Sn}}=N_{\mathrm{Pt}-\mathrm{Sn}} /\left(N_{\mathrm{Pt}-\mathrm{Sn}}+N_{\mathrm{Pt}-\mathrm{Pt}}\right)$ in Table 1$)$. A clear decrease [increase] in the fraction of $\mathrm{Pt}-\mathrm{Pt}$ [Pt-Sn] bonds is observed with decreasing Pt content. More specifically, quasi phase pure $\mathrm{Pt}_{3} \mathrm{Sn}$

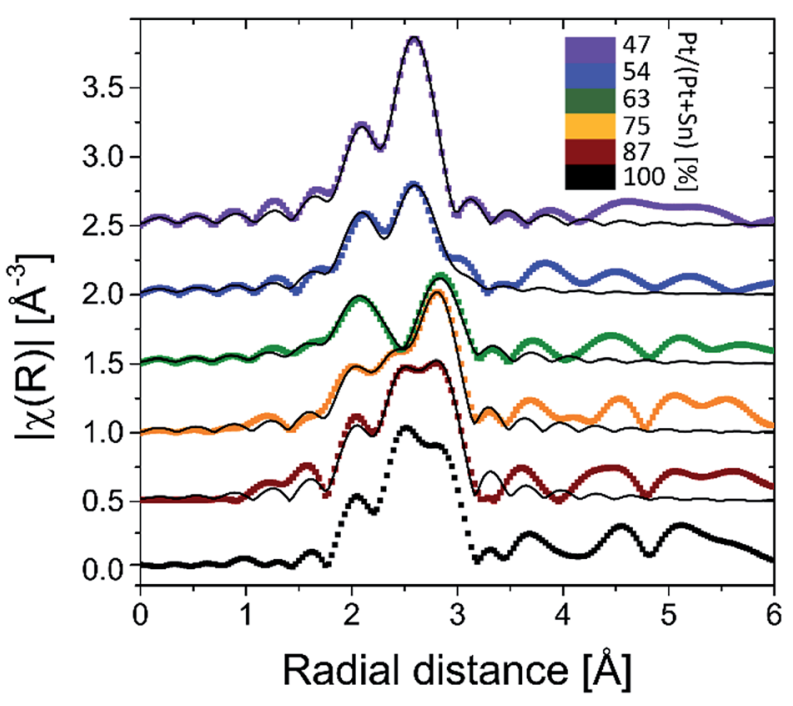

Fig. $3 k^{2}$-Weighted Fourier transformed EXAFS magnitudes of the BMNPs obtained after TPR in $10 \% \mathrm{H}_{2} / \mathrm{N}_{2}$ up to $700{ }^{\circ} \mathrm{C}$. The thin black lines are the EXAFS modeling results ( $\mathrm{Pt}-\mathrm{Pt}+\mathrm{Pt}-\mathrm{Sn}$ shell). 
Table 2 Characterization of Pt-Sn samples with $\mathrm{Pt} /(\mathrm{Pt}+\mathrm{Sn})$ atomic ratio of ca. $75 \%$ prepared for demonstrating the size control. The standard deviation of the particle size distribution is about $25 \%$ of the average particle size

\begin{tabular}{|c|c|c|c|c|}
\hline \multirow[b]{2}{*}{ Sample ID } & \multicolumn{2}{|c|}{$\begin{array}{l}\text { Thickness } \\
\text { (nm) }\end{array}$} & \multirow{2}{*}{$\begin{array}{l}\text { Total thickness } \\
\text { (nm) }\end{array}$} & \multirow{2}{*}{$\begin{array}{l}\text { Average particle } \\
\text { size }(\mathrm{nm})\end{array}$} \\
\hline & $\mathrm{SnO}_{2}$ & $\mathrm{Pt}$ & & \\
\hline I & 0.7 & 0.7 & 1.4 & 5 \\
\hline II & 0.9 & 1.1 & 2.0 & 10 \\
\hline III & 1.3 & 1.4 & 2.7 & 17 \\
\hline IV & 1.5 & 1.7 & 3.2 & 25 \\
\hline $\mathrm{V}$ & 2.8 & 3.0 & 5.8 & 58 \\
\hline
\end{tabular}

(sample b) and PtSn (sample e) display 62 [38] and 20 [80]\% Pt [Sn] coordination around the Pt central absorber, respectively. This is in close accord with the theoretical 67 [33] and $25[75] \%$ $\mathrm{Pt}-\mathrm{Pt}[\mathrm{Pt}-\mathrm{Sn}]$ bond abundance for $\mathrm{Pt}_{3} \mathrm{Sn}$ and PtSn alloy structures. The short-range information derived from EXAFS therefore fully corroborates with the long-range XRD data, proving the high phase-tuning potential of ALD for Pt-Sn alloys.

In addition to phase control, the presented method enables tuning of the Pt-Sn BMNP size. More particularly, particle size control is achieved by scaling the total bilayer film thickness, while keeping the $\mathrm{Pt} /(\mathrm{Pt}+\mathrm{Sn})$ atomic ratio constant. This is demonstrated by the preparation of a series of bilayer films with a constant $\mathrm{Pt} /(\mathrm{Pt}+\mathrm{Sn})$ atomic ratio of $c a .75 \%$, but different total thickness, ranging from 1.4 to $5.8 \mathrm{~nm}$ (Table 2). The films were subjected to a TPR up to $700{ }^{\circ} \mathrm{C}$ in $10 \% \mathrm{H}_{2} / \mathrm{N}_{2}$ and the formation of $\mathrm{Pt}_{3} \mathrm{Sn}$ was confirmed by XRD measurements (see ESI $\dagger$ ). The morphology of the films was studied by scanning electron microscopy (SEM). The SEM images are shown in Fig. 4
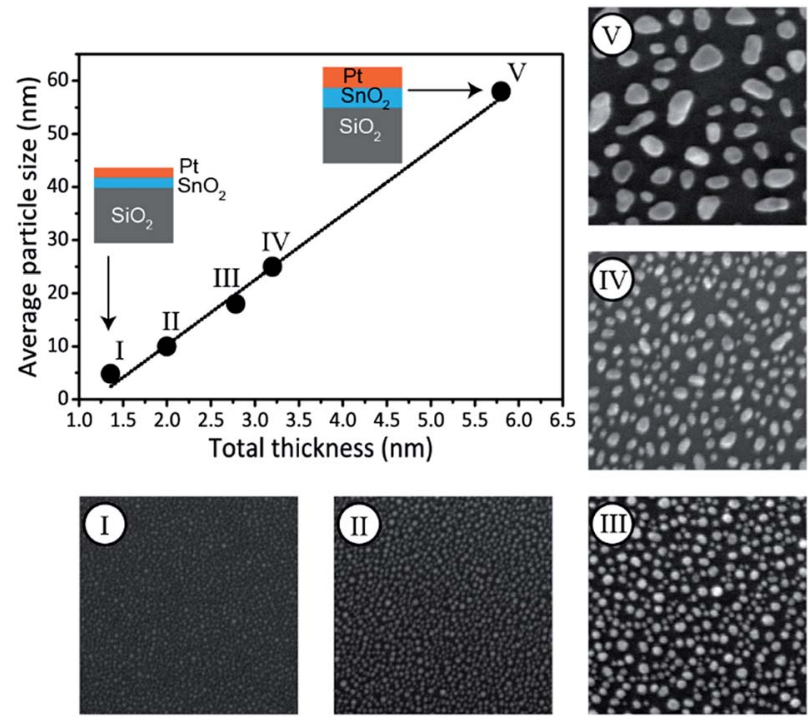

Fig. 4 SEM images (full width of $500 \mathrm{~nm}$ ) measured after TPR in 10\% $\mathrm{H}_{2} / \mathrm{N}_{2}$ up to $700^{\circ} \mathrm{C}$ of $\mathrm{Pt} / \mathrm{SnO}_{2}$ bilayers with $\mathrm{Pt} /(\mathrm{Pt}+\mathrm{Sn})$ atomic ratio of ca. $75 \%$. The graph shows the average BMNP size formed after TPR as determined from SEM analysis versus the total deposited thickness. The line is a linear fit to the data points. The schematics show how the thickness of the $\mathrm{Pt}$ and $\mathrm{SnO}_{2}$ layers is scaled to tune the particle size. together with a plot of the average particle size against the total deposited thickness. A linear relation is observed, proving that the average BMNP size can indeed be tuned via the total thickness of the bilayer ALD-film. While a wide distribution of nanoparticle sizes is observed for the largest nanoparticles in the SEM image of sample V, a narrow particle size distribution is obtained for the smallest nanoparticles that are of highest interest in the field of catalysis (see ESI $\dagger$ ).

\section{Conclusions}

In summary, this work demonstrates that a reductive treatment of $\mathrm{Pt} / \mathrm{SnO}_{2}$ bilayers deposited with ALD results in the formation of alloyed Pt-Sn particles for which the crystalline phase and average particle size can be controlled via the ALD process. The crystalline phase is determined by the asdeposited $\mathrm{Pt} /(\mathrm{Pt}+\mathrm{Sn})$ atomic ratio, while the average particle size is defined by the total $\left(\mathrm{SnO}_{2}+\mathrm{Pt}\right)$ thickness. Therefore, this approach highly takes advantage of the unique monolayer-level thickness control of ALD. Since the phase and size of the Pt-Sn bimetallic nanoparticles can be rationally tuned, we believe that the synthesis method we present here will open up a new way for constructing model systems that enable in-depth investigations of the relation between the Pt-Sn bimetallic particle structure and the catalytic efficiency and selectivity. In a first effort to validate the catalytic applicability of the presented Pt-Sn BMNP synthesis approach during propane dehydrogenation, activities comparable to conventionally synthesized Pt-Sn catalysts were observed. Detailed investigation towards optimization is ongoing.

\section{Acknowledgements}

This research was supported by the Flemish Research Foundation (FWO-Vlaanderen), the Flemish Government (Longterm structural funding - Methusalem funding and Mediumscale research infrastructure funding-Hercules funding), the Special Research Fund BOF of Ghent University (GOA 01G01513), and the IAP7/05 Interuniversity Attraction Poles Programme, Belgian State, Belgian Science Policy. We are also grateful to the SAMBA-SOLEIL staff for smoothly running the facilities.

\section{Notes and references}

1 W. Yu, M. D. Porosoff and J. G. Chen, Chem. Rev., 2012, 112, 5780-5817.

2 J. J. H. B. Sattler, J. Ruiz-Martinez, E. Santillan-Jimenez and B. M. Weckhuysen, Chem. Rev., 2014, 114, 10613-10653.

3 J. Wu, Z. Peng and A. T. Bell, J. Catal., 2014, 311, 161-168.

4 M. Filez, E. A. Redekop, H. Poelman, V. V. Galvita, M. Meledina, S. Turner, G. Van Tendeloo, C. Detavernier and G. B. Marin, Catal. Sci. Technol., 2016, 6, 1863-1869.

5 A. Sapi, F. Liu, X. Cai, C. M. Thompson, H. Wang, K. An, J. M. Krier and G. A. Somorjai, Nano Lett., 2014, 14, 67276730 . 
6 C. Cui, M. Ahmadi, F. Behafarid, L. Gan, M. Neumann, M. Heggen, B. R. Cuenya and P. Strasser, Faraday Discuss., 2013, 162, 91-112.

7 X. Wang, L. Altmann, J. Stöver, V. Zielasek, M. Bäumer, K. AlShamery, H. Borchert, J. Parisi and J. Kolny-Olesiak, Chem. Mater., 2013, 25, 1400-1407.

8 D. Y. Desario and F. J. Disalvo, Chem. Mater., 2014, 26, 27502757.

9 S. M. George, Chem. Rev., 2010, 110, 111-131.

10 V. Miikkulainen, M. Leskelä, M. Ritala and R. L. Puurunen, J. Appl. Phys., 2013, 113, 021301.

11 C. Detavernier, J. Dendooven, S. Pulinthanathu Sree, K. F. Ludwig and J. A. Martens, Chem. Soc. Rev., 2011, 40, 5242.

12 B. J. O'Neill, D. H. K. Jackson, J. Lee, C. Canlas, P. C. Stair, C. L. Marshall, J. W. Elam, T. F. Kuech, J. A. Dumesic and G. W. Huber, ACS Catal., 2015, 5, 1804-1825.

13 K. Cao, Q. Zhu, B. Shan and R. Chen, Sci. Rep., 2015, 5, 8470. 14 J. Lu, K.-B. Low, Y. Lei, J. A. Libera, A. Nicholls, P. C. Stair and J. W. Elam, Nat. Commun., 2014, 5, 3264.

15 S. T. Christensen, H. Feng, J. L. Libera, N. Guo, J. T. Miller, P. C. Stair and J. W. Elam, Nano Lett., 2010, 10, 3047-3051.

16 J. Dendooven, R. K. Ramachandran, K. Devloo-Casier, G. Rampelberg, M. Filez, H. Poelman, G. B. Marin, E. Fonda and C. Detavernier, J. Phys. Chem. C, 2013, 117, 20557-20561.

17 J. Lu, J. W. Elam and P. C. Stair, Surf. Sci. Rep., 2016, 71, 410472.

18 M. J. Weber, M. A. Verheijen, A. A. Bol and W. M. M. Kessels, Nanotechnology, 2015, 26, 94002.
19 M. J. Weber, A. J. M. MacKus, M. A. Verheijen, C. Van Der Marel and W. M. M. Kessels, Chem. Mater., 2012, 24, 29732977.

20 R. K. Ramachandran, J. Dendooven, M. Filez, V. V. Galvita, H. Poelman, E. Solano, M. M. Minjauw, K. Devloo-Casier, E. Fonda, D. Hermida-Merino, W. Bras, G. B. Marin and C. Detavernier, ACS Nano, 2016, 10, 8770-8777.

21 M. N. Mullings, C. Hägglund and S. F. Bent, J. Vac. Sci. Technol., A, 2013, 31, 61503.

22 M. Filez, H. Poelman, R. K. Ramachandran, J. Dendooven, K. Devloo-Casier, E. Fonda, C. Detavernier and G. B. Marin, Catal. Today, 2014, 229, 2-13.

23 Q. Xie, Y.-L. Jiang, C. Detavernier, D. Deduytsche, R. L. Van Meirhaeghe, G.-P. Ru, B.-Z. Li and X.-P. Qu, J. Appl. Phys., 2007, 102, 83521.

24 J. Musschoot, Q. Xie, D. Deduytsche, S. Van den Berghe, R. L. Van Meirhaeghe and C. Detavernier, Microelectron. Eng., 2009, 86, 72-77.

25 W. Knaepen, C. Detavernier, R. L. Van Meirhaeghe, J. Jordan Sweet and C. Lavoie, Thin Solid Films, 2008, 516, 4946-4952.

26 W. Knaepen, S. Gaudet, C. Detavernier, R. L. Van Meirhaeghe, J. J. Sweet and C. Lavoie, J. Appl. Phys., 2009, 105, 83532.

27 D. C. Koningsberger, B. L. Mojet, G. E. van Dorssen and D. E. Ramaker, Top. Catal., 2000, 10, 143-155.

28 M. Filez, E. A. Redekop, V. V. Galvita, H. Poelman, M. Meledina, S. Turner, G. Van Tendeloo, A. T. Bell and G. B. Marin, Phys. Chem. Chem. Phys., 2016, 18, 3234-3243.

29 T. Biggs, S. S. Taylor and E. Van Der Lingen, Platinum Met. Rev., 2005, 49, 2-15. 